M33 LONG-TERM EFFICACY OF NINTEDANIB IS MAINTAINED IN PATIENTS WITH IDIOPATHIC PULMONARY FIBROSIS (IPF) IRRESPECTIVE OF DOSE: SUBGROUP ANALYSIS OF INPULSIS-ON

${ }^{1} \mathrm{~B}$ Crestani, ${ }^{2} \mathrm{M}$ Kolb, ${ }^{3} \mathrm{~B}$ Wallaert, ${ }^{4} \mathrm{M}$ Quaresma, ${ }^{5} \mathrm{~W}$ Stansen, ${ }^{6} \mathrm{~L}$ Richeldi. ${ }^{7}$ Hôpital Bichat, Pneumologie, Paris, France; ${ }^{2}$ McMaster University, Hamilton, Ontario, Canada; ${ }^{3}$ University Hospital of Lille, Lille, France; ${ }^{4}$ Center for Interstitial and Rare Lung Diseases, Pneumology, Thoraxklinik, University of Heidelberg, and Translational Lung Research Centre Heidelberg, German Centre for Lung Research, Heidelberg, Germany; ${ }^{5}$ Boehringer Ingelheim Pharma GmbH and Co. KG, Ingelheim am Rhein, Germany; ${ }^{6}$ Catholic University of the Sacred Heart, Rome, Italy

\subsection{6/thoraxjnl-2017-210983.455}

Introduction and Aim In the INPULSIS trials, nintedanib reduced the annual rate of decline in FVC versus placebo in patients with IPF $(-113.6$ versus $-223.5 \mathrm{~mL} / \mathrm{year})$. Patients completing the 52 week treatment period could receive openlabel nintedanib in an extension trial (INPULSIS-ON). Patients receiving nintedanib or placebo $150 \mathrm{mg}$ bid at the end of INPULSIS received nintedanib $150 \mathrm{mg}$ bid in INPULSIS-ON; patients receiving nintedanib or placebo $100 \mathrm{mg}$ bid at the end of INPULSIS received nintedanib $100 \mathrm{mg}$ bid or $150 \mathrm{mg}$ bid in INPULSIS-ON, based on patient/investigator discussions. Dose reduction from $150 \mathrm{mg}$ bid to $100 \mathrm{mg}$ bid was allowed to manage adverse events; re-escalation to $150 \mathrm{mg}$ bid was permitted. Our objective was to assess whether dose influenced the effect of nintedanib on FVC decline in INPULSISON.

Methods The annual rate of decline in FVC over 96 weeks in INPULSIS-ON was assessed in subgroups of patients by whether they were treated with nintedanib $150 \mathrm{mg}$ bid only, $100 \mathrm{mg}$ bid only, or both $150 \mathrm{mg}$ bid and $100 \mathrm{mg}$ bid. All available FVC measurements collected at time points between baseline and week 96 were used to calculate FVC decline. These analyses were descriptive and based on a data snapshot in October 2015.

Results A total of 734 patients received nintedanib in INPULSIS-ON: 436 patients (59.4\%) received nintedanib $150 \mathrm{mg}$ bid, 53 patients $(7.2 \%)$ received nintedanib $100 \mathrm{mg}$ bid, and 245 patients $(33.4 \%)$ received both doses. The annual rates of decline in FVC over 96 weeks were -116.4 (8.9) $\mathrm{mL} / \mathrm{year}$, -79.0 (30.1) $\mathrm{mL} /$ year, and $-126.2(11.4) \mathrm{mL} /$ year in patients treated with nintedanib $150 \mathrm{mg}$ bid, $100 \mathrm{mg}$ bid, or both doses, respectively, and were consistent with the annual rate of decline in FVC over 96 weeks in all patients treated with nintedanib $(-117.8[6.8] \mathrm{mL} /$ year$)$.

Conclusion Data from INPULSIS-ON demonstrated that the annual rate of decline in FVC was similar in patients treated with nintedanib $150 \mathrm{mg}$ bid, $100 \mathrm{mg}$ bid, or both doses. The long-term efficacy of nintedanib in reducing disease progression was maintained in patients with IPF who required dose adjustments to manage adverse events.

Please refer to page A262 for declarations of interest in relation to abstract M33.

\title{
M34 CARDIOVASCULAR SAFETY OF NINTEDANIB IN SUBGROUPS BY CARDIOVASCULAR RISK AT BASELINE IN THE TOMORROW AND INPULSIS TRIALS
}

${ }^{1}$ I Noth, ${ }^{2} \mathrm{M}$ Wijsenbeek, ${ }^{3} \mathrm{M}$ Kolb, ${ }^{4} \mathrm{~F}$ Bonella, ${ }^{5} \mathrm{~L}$ Moros, ${ }^{5} \mathrm{D}$ Wachtlin, ${ }^{6} \mathrm{TJ}$ Corte. ${ }^{1}$ Pulmonary and Critical Care Medicine, University of Chicago, Chicago, US; ${ }^{2}$ Erasmus MC, University Medical Centre, Rotterdam, Netherlands; ${ }^{3}$ McMaster University, Hamilton, Canada; ${ }^{4}$ Interstitial and Rare Lung Disease Unit, Ruhrlandklinik, University Hospital, University of Duisburg-Essen, Essen, Germany; ${ }^{5}$ Boehringer Ingelheim Pharma GmbH and Co.KG, Ingelheim am Rhein, Germany; ${ }^{6}$ Royal Prince Alfred Hospital, Camperdown, New South Wales, Australia

\subsection{6/thoraxjnl-2017-210983.456}

Introduction and Aim Nintedanib is a tyrosine kinase inhibitor, a drug class that may be associated with increased risk of arterial thromboembolic events. The efficacy and safety of 52 weeks' treatment with nintedanib versus placebo in patients with IPF were assessed in the TOMORROW and INPULSIS trials. Patients with myocardial infarction in the previous 6 months, unstable angina in the previous month, or stroke in the previous year were excluded. We assessed the effect of $\mathrm{CV}$ risk at baseline on the CV safety of nintedanib $150 \mathrm{mg}$ bid.

Methods Incidence rates of major adverse CV events (MACE) in subgroups of patients with a history of atherosclerotic CV disease and/or $\geq 1 \mathrm{CV}$ risk factor at baseline (higher $\mathrm{CV}$ risk), and patients with no history of atherosclerotic CV disease and no CV risk factors at baseline (lower CV risk), were analysed using pooled data from the TOMORROW and INPULSIS trials. CV risk factors were defined as hypertension, dyslipidaemia, BMI $\geq 30 \mathrm{~kg} / \mathrm{m}^{2}$, current/former smoking, and diabetes. MACE were based on fatal adverse events included in the system organ classes "cardiac disorders" and "vascular disorders" in MedDRA; events in the subordinate standardised MedDRA query (SMQ) "myocardial infarction"; stroke based on selected preferred terms from the subordinate SMQs "haemorrhagic cerebrovascular conditions" and "ischaemic cerebrovascular

N Patients with

events, $\mathbf{n}(\%)$

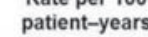

$$
\text { (95\% CI) }
$$

\section{Higher CV risk}

Nintedanib

Placebo

Lower CV risk

Nintedanib

Placebo

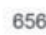

451

$23(3.5)$

$15(3.3)$

67

57

$$
\begin{aligned}
& 3(4.5) \\
& 3(5.3)
\end{aligned}
$$

$3.88(2.58,5.84)$

$3.49(2.10,5.79)$

$4.78(1.54,14.82)$

$5.37(1.73,16.65)$
Rate per 100 patient-years $(95 \% \mathrm{Cl})$

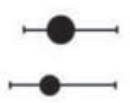

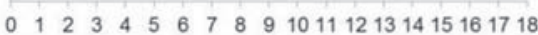


conditions"; and MedDRA preferred terms "sudden death", "cardiac death" and "sudden cardiac death".

Results At baseline, 1107 (89.9\%) patients (656 nintedanib, 451 placebo) had higher CV risk and 124 (10.1\%) patients (67 nintedanib, 57 placebo) had lower $\mathrm{CV}$ risk. In patients with higher CV risk, incidence rates $(95 \% \mathrm{CI})$ of MACE were $3.88(2.58,5.84)$ and $3.49(2.10,5.79)$ per 100 patient-years in the nintedanib and placebo groups, respectively. In patients with lower CV risk, incidence rates $(95 \% \mathrm{CI})$ of MACE were
$4.78(1.54,14.82)$ and $5.37(1.73,16.65)$ per 100 patientyears in the nintedanib and placebo groups, respectively.

Conclusion In pooled data from the TOMORROW and INPULSIS trials, the incidence of MACE was similar between the nintedanib and placebo groups in patients with higher CV risk at baseline and in patients with lower CV risk at baseline.

Please refer to page A262 for declarations of interest in relation to abstract M34. 


\section{Declarations of Interest}

\section{S6 ESTABLISHING THE TRUE INCIDENCE OF HOSPITALISED COMMUNITY ACQUIRED PNEUMONIA (CAP) IN THE UK: A HOSPITAL EPISODE STATISTICS (HES) ANALYSIS}

10.1136/thoraxjnl-2017-210983.457

This research was sponsored by Pfizer.

J Campling, D Jones, G Ellsbury, C Czudek, and H Madhava are employees of Pfizer and have no conflicts of interest to declare.

M Slack has received personal fees from GSK, Pfizer, AstraZeneca and Sanofi Pasteur as a speaker at international meetings and as a member of advisory boards (outside the scope of the submitted work). She has also worked as a contractor for Pfizer. HES analyses were done by Harvey Walsh Health Informatics, and medical writing support was provided by Richard Watt at Sudler, both of which were funded by Pfizer.

\section{S93 EFFECT OF LUMACAFTOR/IVACAFTOR ON TOTAL, BRONCHIECTASIS, AND AIR TRAPPING COMPUTED TOMOGRAPHY (CT) SCORES IN CHILDREN HOMOZYGOUS FOR F508DEL-CFTR: EXPLORATORY IMAGING SUBSTUDY}

\subsection{6/thoraxjnl-2017-210983.458}

AS Brody reports personal fees from Vertex Pharmaceuticals during the conduct of the study.

$S$ Nagle reports personal consulting fees from Vertex Pharmaceuticals during the conduct of the study; non-financial support from GE Healthcare (institution/department support).

C Hug, G Marigowda, D Waltz, L Wang are employees of Vertex Pharmaceuticals and may hold stock and/or stock options in the company.

J Goldin reports 'other' conflicts - Founder of MedQIA during the conduct of the study.

F Ratjen reports grants and personal fees from Vertex Pharmaceuticals, personal consulting fees from Novartis, Bayer, Roche, Genetech, and Prosteostasis.

\section{S96 AN OPEN-LABEL EXTENSION (EXT) STUDY OF LUMACAFTOR/IVACAFTOR (LUM/IVA) THERAPY IN PATIENTS AGED 6 TO 11 YEARS WITH CYSTIC FIBROSIS (CF) HOMOZYGOUS FOR F508DEL-CFTR}

\subsection{6/thoraxjnl-2017-210983.459}

$\mathrm{M}$ Chilvers and $\mathrm{P}$ Black have nothing to disclose.

S Tian, G Marigowda, M Bsharat, C Hug are employees of Vertex Pharmaceuticals and may hold stock and/or stock options in the company.

M Solomon reports involvement in clinical trials with Vertex Pharmaceuticals. (sponsored the clinical trial, no money directly to PI)

M Rosenfeld reports that her institution has received funding from Vertex Pharmaceuticals for research on which she is an investigator. She also has served as a consultant for Vertex Pharmaceuticals.

G Sawicki reports personal fees from Vertex Pharmaceuticals outside the submitted work. (advisory boards)

J Hoppe reports grant funding from the Cystic Fibrosis Foundation outside the submitted work.

\section{P19 IMPACT OF MONTH OF INITIATION OF OMALIZUMAB ON TREATMENT OF SEVERE ALLERGIC ASTHMA, A SUB- ANALYSIS OF THE APEX II STUDY}

10.1136/thoraxjnl-2017-210983.460

$\mathrm{R}$ Niven has received an unrestricted grant of $£ 10,000$ from Novartis in 2010 towards development of clinical services at the University Hospital of South Manchester. He has run preceptorship programmes in 2015 and 2106. These programmes have resulted in payment to the University Hospital of south Manchester for amounts not exceeding $£ 10,000$. Dr Niven has also performed lecturing at Pharmaceutically sponsored meetings for the following pharmaceutical companies in the last 3 years:- Astra Zeneca $(<£ 1,000)$, Boehringer Ingelheim $(<£ 2,000)$ Boston scientific $(<£ 5,000)$ Chiesi $(<£ 1,000)$, Novartis $<£ 10,000$, Napp $(<£ 2,000)$, Teva $(<£ 2,000)$. Dr Niven has sat on advisory boards for the following companies in the last 3 years, (Astra Zeneca, Boehringer Ingelheim, Boston scientific, Chiesi, GSK, Novartis Vectura and Teva), receiving reimbursement not exceeding $£ 5,000$ per company. Dr Niven has received sponsorship support to attend international academic meetings from Astra Zeneca, Boehringer ingelheim, Novartis, GSK, Chiesi and TEVA. Dr Niven, (or any members of his family) has no shares or any pecuniary interest in any pharmaceutical industry and has no share holdings or dividends and is not a paid consultant for any company.

D Saralaya has no conflicts of interest pertaining to this abstract

$\mathrm{R}$ Chaudhuri has been a member of advisory board meetings for Novartis, Astraeneca, GSK and Teva, been invited to international conferences by Novartis, Boehringer, AstraZeneca and Napp and received educational research grants from Novartis and Aerocrine.

M Masoli attended a Novartis advisory board meeting.

I Clifton has received honoria from Novartis, and GSK. He has received travel grants to attend educational meetings from Novartis, GSK, Gilead and AstraZeneca.

$\mathrm{AH}$ Mansur has received personal and institutional payments for speaking, participation in advisory board meetings and other education activities from several pharmaceutical companies that include AZ, GSK, BI, Novartis, Teva, NAPP, Chiesi

S Hollywood Employee at Novartis. This study was funded by Novartis, who participated in the study design, interpretation of data, and review and approval of the abstract.

$\mathrm{S}$ Mclain-Smith employee of $\mathrm{pH}$ Associates; carried out data analysis and provided medical writing support.

A Menzies-Gow has attended advisory boards for GlaxoSmithKline, Novartis, AstraZeneca, Boehringer Ingelheim, and Teva. He has received speaker fees from Novartis, AstraZeneca, Vectura, Boehringer Ingelheim, and Teva. He has received clinical trial funding from AstraZeneca and has participated in research with Hoffmann La Roche, GlaxoSmithKline, and Boehringer Ingelheim, for which his institution has 